\title{
When doctors smoke
}

Tobacco Control has commented editorially on the important role doctors can play in helping patients to stop smoking. ${ }^{1}$ A point deserving equal emphasis, especially in light of the article about French doctors in this issue of the journal, ${ }^{2}$ is the problem of smoking by doctors.

Substantial progress has been made in many industrialised countries in reducing smoking prevalence among doctors. For example, a 1988 survey of a random sample of 5000 British general practitioners (GPs) showed that only $4.3 \%$ were cigarette smokers. ${ }^{3}$ In a 1987 survey of a random sample of 1000 physicians in the United States (US), ${ }^{4} 9 \%$ answered "yes" to the question "Do you smoke?" (ie, no distinction was made in the question between cigarette smoking and pipe/cigar smoking).

Unfortunately, high smoking rates among doctors persist in several industrialised countries, and may represent the norm in developing regions. As Tessier et al ${ }^{2}$ have shown in this issue of Tobacco Control, $32 \%$ of GPs in France reported smoking cigarettes in 1991. Even higher smoking rates among doctors have been found in other countries. Adriaanse and van Reek reported figures (some of which may be outdated) exceeding $50 \%$ for male doctors in Portugal, Greece, The Netherlands, Italy, Germany, Turkey, and Poland; and for female doctors in Spain, Italy, and Turkey. ${ }^{5}$

Knowledge of the prevalence of smoking among doctors is useful for at least two reasons. First, such information may indicate the likelihood of success of population-based anti-tobacco campaigns. In countries where a high proportion of doctors smoke, it will be difficult to convince the general population of the serious health consequences of smoking. "How bad could smoking be", people will ask, "if so many doctors smoke?"

Second, the prevalence of smoking among doctors may reflect the "maturity" of the smoking epidemic in a particular country. Michael Kunze has developed a twophase model of the maturity of a country's smoking epidemic (figure) ${ }^{6}$ Before the hazards of smoking become well known in a society (phase 1), doctors take up smoking earlier and to a greater extent than the general population, mainly because they have more disposable income to spend on tobacco. During this phase, the ratio of smoking prevalence (doctors/general population) is greater than one. At this stage the society's smoking epidemic might be considered "immature".

As the dangers of smoking become better known, the medical profession begins to give up smoking earlier than the general population. This is because: 1) doctors hear "the message" more quickly, 2) an intolerable contradiction develops between their devotion to health and the self-destructive nature of their smoking, and 3) smoking may become stigmatised in medical circles long before it becomes so in society at large.

When the prevalence of smoking among doctors falls below that of the general population (phase 2), the country's smoking epidemic might be considered "mature". During this phase, smoking prevalence in the general population will continue to increase for a time, but will eventually level off and then begin a steady decline as the hazards of smoking become more well known, as tobacco control policies are adopted, and as smoking becomes more socially unacceptable.

In this model, the epidemic of smoking-attributable disease

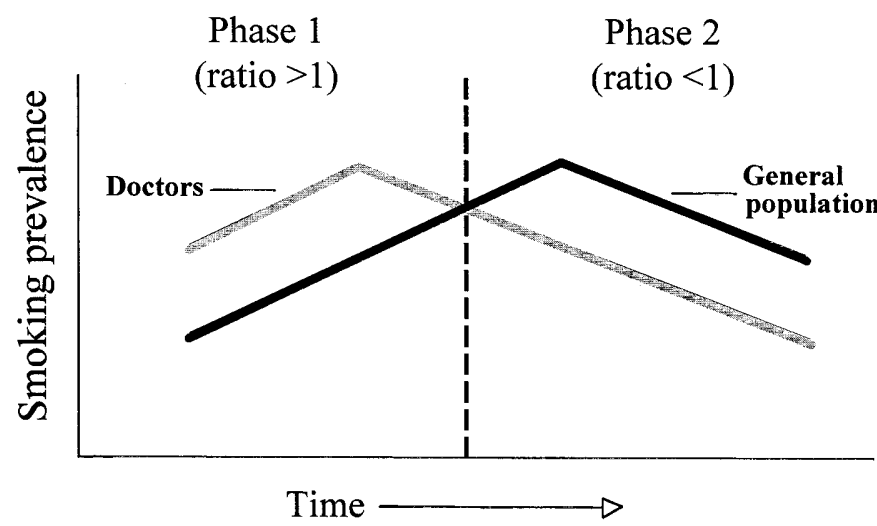

Figure Two-phase model of the maturity of a country's smoking epidemic. "Ratio" refers to the ratio of smoking prevalence among doctors to the prevalence in the general population. Source: Michael Kunze. ${ }^{6}$

would probably begin during the middle or later part of phase 1 , and would continue into phase 2 for at least a few decades. Only after two or three decades of declining smoking rates in the general population would smokingattributable disease begin to level off and then fall.

The World Health Organisation (WHO) recently published figures for 14 countries comparing smoking prevalence among GPs to the prevalence among the general population. ${ }^{7}$ Those figures, along with data for the United Kingdom and the US, are provided in the table. Five of these countries - Luxembourg, Japan, Spain, Italy, and Portugal-have a higher smoking prevalence among physicians than among the general population; in other words, their smoking epidemics are still at an "immature" stage (phase 1 of the Kunze model) according to the data in the table.

However, applying data to the model is problematic if those data do not take into account differences in the sex distribution of physicians compared with the general public. For example, in countries where smoking prevalence is much higher in males and where most doctors are male, the ratio of smoking prevalence (doctors/general population) will be artifactually high. Ideally, smoking prevalence figures for doctors and the general population should be adjusted to account for differences in the sociodemographic make-up (eg, sex and age distribution) of the two populations before those figures are applied to the model.

It would be useful to test the validity of the model. This could be done by plotting time trends, for several different countries, in: 1) smoking prevalence among doctors and among the general population (adjusting for sociodemographic differences between the two populations, as mentioned above), 2) public awareness of the health hazards of smoking, 3 ) the incidence of or mortality from diseases caused by smoking, and 4) measures of tobacco control.

So far in this editorial, I have been discussing smoking among doctors in a societal context. But of course the problem of smoking by doctors is critically important at the level of the doctor-patient encounter. Just as people will minimise the dangers of smoking when they see many 
Table Prevalence of smoking among general practitioners and the general population, selected countries, circa 1990

\begin{tabular}{lccc}
\hline Country & GPs (\%) & $\begin{array}{c}\text { General } \\
\text { population }(\%)\end{array}$ & $\begin{array}{c}\text { Ratio of smoking } \\
\text { prevalence } \\
\text { (GPs/population) }\end{array}$ \\
\hline UK (1988) & 4 & 32 & 0.13 \\
US (1987) & $9^{\star}$ & 29 & 0.31 \\
Ireland & 20 & 37 & 0.54 \\
Hungary (1989) & 21 & 34 & 0.62 \\
Netherlands & 29 & 45 & 0.64 \\
Belgium & 29 & 39 & 0.74 \\
Germany & 25 & 32 & 0.78 \\
Brazil (1989) & 25 & 31 & 0.81 \\
Denmark & 38 & 45 & 0.84 \\
France & $31 \star \star$ & 35 & 0.89 \\
Greece & 39 & 42 & 0.93 \\
Luxembourg & 36 & 33 & 1.09 \\
Spain & 45 & 41 & 1.10 \\
Japan & 44 & 38 & 1.16 \\
Italy & 41 & 33 & 1.24 \\
Portugal & 39 & 27 & 1.44 \\
\hline
\end{tabular}

Sources: World Health Organisation ${ }^{7}$, except for the $\mathrm{UK}^{3,8}$ and the US ${ }^{4,9}$

$\star$ From a random sample of 1000 physicians, selected from among all physicians in the country (ie, not just general practitioners)

$\star \star$ Reported as $32 \%$ by Tessier et al for $1991 .^{2}$

doctors who smoke, so will the individual patient when he sees his doctor smoking.

In the first half of this century, when the smoking epidemic in the US was "immature", doctors not only smoked but appeared in cigarette advertisements. One infamous ad campaign proclaimed that "More doctors smoke Camels than any other cigarette" ${ }^{10}$ But as the US smoking epidemic began to mature, the message changed. In the late 1960s, the Public Health Service produced and disseminated a simple black-and-white poster that stated in bold letters, " 100000 Doctors Have Quit Smoking Cigarettes". Small print at the bottom of the poster explained, "maybe they know something you don't". The power of that message should not be lost on anyone who works in tobacco control, particularly those who work in countries with an "immature" smoking epidemic.

RONALD M DAVIS

Editor
1 Fowler G. Educating doctors in smoking cessation. Tobacco Control 1993; $2: 5-6$

2 Tessier JF, René L, Nejjari C, Belougne D, Moulin J, Fréour P. Attitudes and opinions of French general practitioners towards tobacco. Tobacco Control 1993;2:226-30.

3 Fowler G, Mant D, Fuller A, Jones L. The "Help your patient to stop" initiative: evaluation of smoking. prevalence and dissemination of initiative: evaluation of smoking prevalence and dissemination of

4 Harvey L, Shubat S. Physician opinion on health care issues, 1987. In: AMA surveys of physician and public opinion on health care issues, 1987.
arvey $\mathrm{L}$, Shubat $\mathrm{S}$. Physician opinion on health care issues, 1987. In: Chicago: American Medical Association, 1987: 31.

5 Adriaanse H, Van Reek J. Physicians' smoking and its exemplary effect. Scand $\mathcal{F}$ Prim Health Care 1989; 7 : 193-6.

6 Kunze M. Current smoking habits in Europe. Presented at the European Conference on Tobacco Priorities \& Strategies, organised by the International Union Against Cancer and the Dutch Foundation on Smoking and Health, 1-3 November 1989, The Hague, The Netherlands.

7 Once burnt twice shy: physicians are smoking less and less. In Briefing material for the media. World No-Tobacco Day, 31 May 1993 (Health material for the media. World No-Tobacco Day, 31 May 1993 (Health services : our window to a tobacco-free world). Geneva, Switzerland: World

8 Reid DJ, Killoran AJ, McNeill AD, Chambers JS. Choosing the most effective health promotion options for reducing a nation's smoking prevalence. Tobacco Control 1992; 1 : 185-96.

Centers for Disease Control. Tobacco use by adults - United States, 1987. $M M W R$ 1989; 38: 685-7.

10 Kawane H, Davis RM. When doctors advertised cigarettes. Tobacco Control 1993; $2: 45$. 